Florida International University FIU Digital Commons

7-6-2016

\title{
A qualitative assessment of what comprises an effective and positive supervisor-student clinician relationship in speech-language pathology
}

Jessica Atick Fencel

Florida International University, jatic001@fiu.edu

DOI: $10.25148 /$ etd.FIDC000748

Follow this and additional works at: https:// digitalcommons.fiu.edu/etd

Part of the Speech Pathology and Audiology Commons

\section{Recommended Citation}

Fencel, Jessica Atick, "A qualitative assessment of what comprises an effective and positive supervisor-student clinician relationship in speech-language pathology" (2016). FIU Electronic Theses and Dissertations. 2574.

https://digitalcommons.fiu.edu/etd/2574 


\section{FLORIDA INTERNATIONAL UNIVERSITY}

Miami, Florida

\section{A QUALITATIVE ASSESSMENT OF WHAT COMPRISES AN EFFECTIVE AND POSITIVE SUPERVISOR-STUDENT CLINICIAN RELATIONSHIP IN SPEECH- \\ LANGUAGE PATHOLOGY}

A thesis submitted in partial fulfillment of the

requirements for the degree of

MASTER OF SCIENCE

in

SPEECH-LANGUAGE PATHOLOGY

by

Jessica Atick Fencel

2016 
To: Dean Ora Strickland

College of Nursing and Health Sciences

This thesis, written by Jessica Atick Fencel, and entitled, A Qualitative Assessment of What Comprises an Effective and Positive Supervisor-Student Clinician Relationship in Speech-Language Pathology, having been approved in respect to style and intellectual content, is referred to you for judgment.

We have read this thesis and recommend that it be approved.

Monica S. Hough

Eliane Ramos

Jean Mead, Major Professor

Date of Defense: July 6, 2016

The thesis of Jessica Atick Fencel is approved.

Dean Ora Strickland

College of Nursing and Health Sciences

Andrés G. Gil

Vice President for Research and Economic Development and Dean of the University Graduate School

Florida International University, 2016 
(C) Copyright 2016 by Jessica Atick Fencel

All rights reserved. 


\author{
ABSTRACT OF THE THESIS \\ A QUALITATIVE ASSESSMENT OF WHAT COMPRISES AN EFFECTIVE AND POSITIVE \\ SUPERVISOR-STUDENT CLINICIAN RELATIONSHIP IN SPEECH-LANGUAGE \\ PATHOLOGY \\ by \\ Jessica Atick Fencel \\ Florida International University, 2016 \\ Miami, Florida \\ Professor Jean Mead, Major Professor
}

The purpose of this study was to gain a better understanding of the factors that constitute a positive and negative supervisor-supervisee relationship as perceived by speech-language pathology graduate students. Clinical practicum experiences were analyzed using qualitative methods via recorded in-depth participant interviews. After the data were collected and transcribed, the narratives were analyzed to draw useful inferences and discover underlying themes using a phenomenological methodology approach.

Two overlaying themes, ASHA's Task 1 of Supervision and Anderson's Continuum Model of Supervision, were identified from the participants' interviews and were used to categorize the data. Results indicate the most likely factors attributed to a positive clinical experience included constructive feedback, respect, positive praise, clear expectations and structured clinical guidance while the factors that were most likely attributed to a negative experience were lack of constructive feedback, lack of perceived respect, negative criticism, unclear expectations, and minimal clinical guidance. 


\section{TABLE OF CONTENTS}

CHAPTER

PAGE

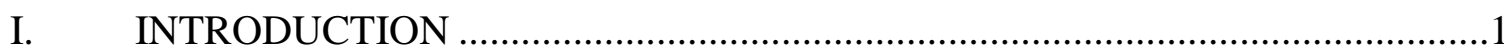

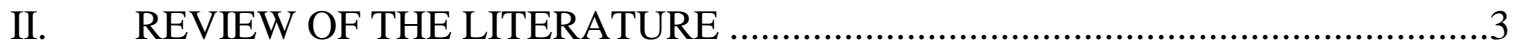

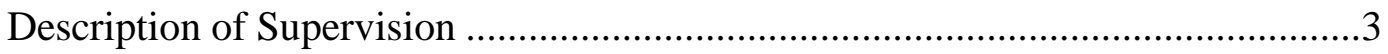

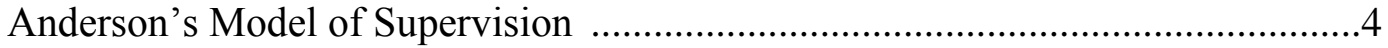

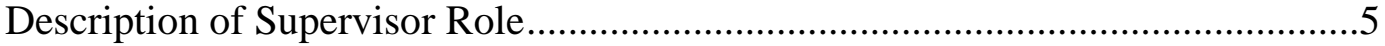

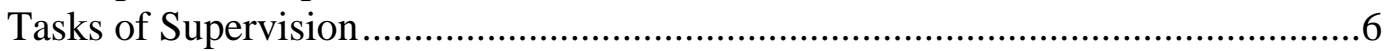

Supervisor-Supervisee Relationship .............................................................

Effects of Negative Supervisory Experiences..................................................12

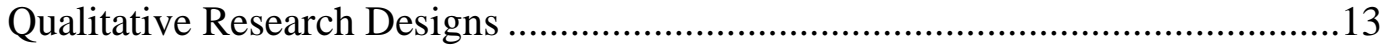

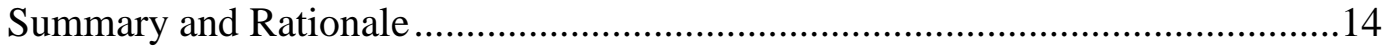

Plan of Study and Experimental Research Questions ....................................15

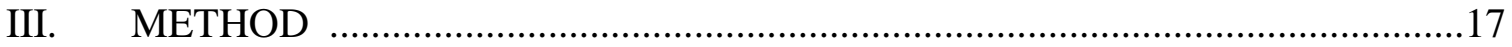

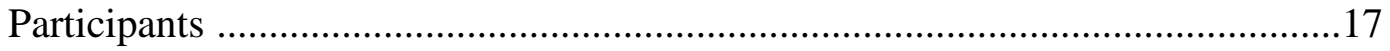

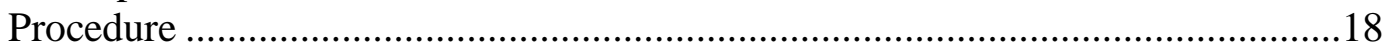

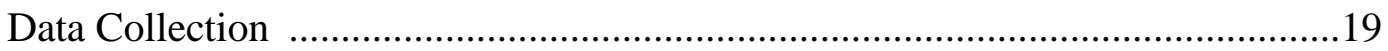

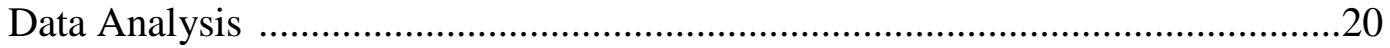

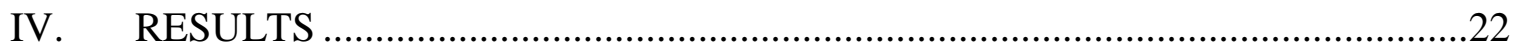

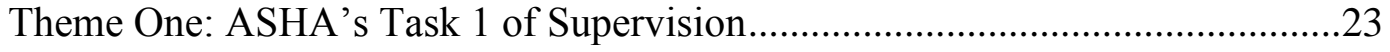

Theme Two: Anderson's Continuum Model of Supervision................................40

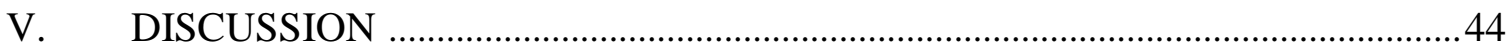

Theme One: ASHA's Task 1 of Supervision........................................................45

Theme Two: Anderson's Continuum Model of Supervision................................49

Limitations of the Study........................................................................49

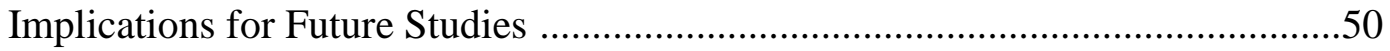

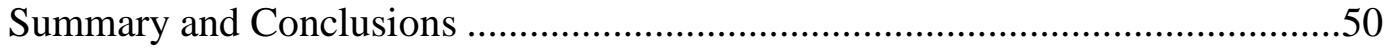

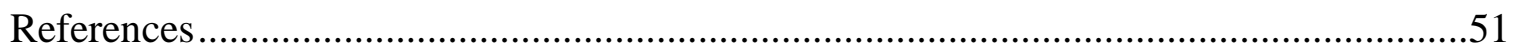

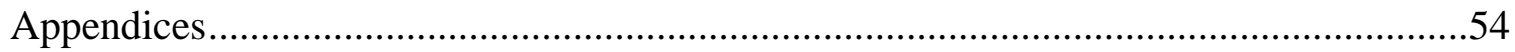




\section{CHAPTER I}

\section{INTRODUCTION}

In the field of speech-language pathology, clinical supervision is a crucial aspect in the pre-professional education of graduate students. According to the American Speech Language Hearing Association, clinical supervision is defined as the "tasks and skills of clinical teaching related to the interaction between a clinician and client" (ASHA, 1985, p. 2). Clinical supervision experience should provide graduate students with an opportunity to work with clients with a variety of communication disorders across different settings. Additionally, supervision should incorporate clinical teaching which encourages the supervisee to use critical thinking, problem-solving skills, and selfevaluation to enhance their own abilities (Anderson, 1988). This experience is supported by the supervisor who provides the student with the clinical training necessary to develop clinical and professional knowledge and skills (Newman, 2005).

The purpose of this study is to gain a better understanding of the factors that constitute a positive and negative supervisor-student clinician relationship as perceived by graduate students. This information was attained by asking graduate students to provide a narrative about their positive or negative supervisory experiences. The focus was be to determine common themes and descriptors that arise from the collection of narratives. This is significant because it will provide us with information that would allow us to enhance the clinical experiences that shape future clinicians in the field.

A review of literature on clinical supervisor-student relationships will be conducted to support this investigation. This review will entail a description of supervision, supervision models and clinical supervisors in the field of speech-language 
pathology. Additionally, this will include a discussion on supervisor-student relationships, students' perceptions regarding supervisory behaviors and relevant research studies which describe the positive and/or negative outcomes of supervision on supervisees. This review will conclude with a description of the goals and rationale for the proposed study, as well as the specific experimental questions which will be under investigation. 


\section{CHAPTER II \\ REVIEW OF THE LITERATURE}

\section{Description of Supervision}

Supervision is necessary and present in all fields in which people work together in a hierarchical structure in which one individual has "authority, influence or power over another" (Anderson, 1988, p. 10). The general purpose of supervision is to develop a relationship in which the supervisor can share information and techniques about what the supervisee needs to provide quality services to clients. It is a mentorship experience in which the supervisee is trained to assume the roles and responsibilities of his or her mentor in that specific field.

In speech-language pathology, supervision is defined as a, "process that consists of a variety of patterns of behavior... which depends upon the needs, competencies, expectations, and philosophies of the supervisor and the supervisee and the specifics of the situation" (Anderson, 1988, p.12). Over time, this definition from Anderson was updated and expanded by ASHA (2008) to include the following:

Professional growth and development of the supervisee and the supervisor are enhanced when supervision or clinical teaching involves self-analysis and selfevaluation. Effective clinical teaching also promotes the use of critical thinking and problem-solving skills on the part of the individual being supervised. (p. 3) Therefore, in the field of speech-language pathology, clinical supervision is not only a critical area of practice but it is a significant component of the professional development of both supervisees and supervisors. 


\section{Anderson's Model of Supervision}

In 1988, Jean Anderson proposed a model of supervision, which is now one of the most prominent models in the field of speech-language pathology, known as the continuum model. Anderson (1988) asserted that supervision exists on a continuum and thereby it, "mandates a change over time in the amount and type of involvement of both the supervisor and the supervisee in the supervisory process" (p. 14). Consequently, supervision should be a process which utilizes different strategies and levels of supervisor involvement depending on the type of situation. Therefore, the supervisor is gradually decreasing his or her involvement in therapy sessions so that the supervisee can learn to become more independent.

There are three major stages in the continuum model: Evaluation-Feedback Stage, Transitional Stage, and Self-Supervision Stage. The Evaluation-Feedback Stage is at the start of the continuum and is a more supervisor dominant method of supervision. The student clinician is typically new to the clinical setting and the supervisor provides more direct support by modeling and coaching the student clinician. As success permits, the supervisor reduces involvement and encourages the student clinician to self-evaluate. The next step on the continuum is the Transitional Stage which requires collaboration between the supervisor and student clinician. At this point, the student clinician is more experienced and can work independently to a certain degree. The supervisor can provide direction, joint problem solving, and interaction as needed. The goal is to encourage the student clinicians to evaluate their own work and train them to utilize problem-solving and critical thinking skills. The final step is the Self-Supervision Stage in which the student clinician is no longer dependent on the supervisor for observation, analysis and 
feedback. Student clinicians should be able to accurately evaluate their own behaviors and make modifications as needed. The supervisor may also be consulted during this stage; however, the student clinician is no longer completely reliant on the supervisor. It is important to note that this stage may be achieved for specific types of clients of certain ages and disorders and not others.

The success of the continuum model is influenced by the supervisor's awareness of the supervisee's knowledge, skills, and needs and their ability to modify their supervisory style in response to these needs. The ultimate goal of clinical teaching in this supervisory model is to promote self-evaluation and self-analysis in the supervisee. Furthermore, the development of the aforementioned skills should also result in enhanced critical thinking and problem-solving skills in the supervisee. The continuum model outlines the goals of supervision; yet the specific factors of clinical supervision that result in positive and effective supervisor-student clinician relationship need to be further examined.

\section{Description of Supervisor Role}

The Committee on Supervision in Speech-Language Pathology and Audiology asserts that a supervisor is an "individual who engage[s] in clinical teaching through observation, conferences, review of records and other procedures, and which is related to the interaction between a clinician and a client and the evaluation or management of communication skills" (ASHA, 1978, p.479). Consequently, the supervisee will be expected to learn to use critical thinking, problem-solving skills, and self-evaluation to enhance his or her own clinical skills and abilities.

According to ASHA's (2008) standards, only individuals with comprehensive knowledge of the field and strong clinical competence, as demonstrated by maintaining 
an active Certificate of Clinical Competence (CCC), may be supervisors. At this time, formal training and a set number of years of experience in the field are not required for an individual to become a supervisor (ASHA 2008, Geller, 2014; Geller \& Foley, 2009). There has been some controversy regarding the need for formal training for supervision (McCrea \& Brasseur, 2003, O’Connor, 2008). Specifically, when comparing trained supervisors with untrained supervisors, McCrea and Brasseur (2003) found that trained supervisors are more effective.

In 2012, an ASHA-appointed Ad Hoc Committee of Supervision recognized the importance of formal training for supervision and proposed the development of a training program for future supervisors (McCrea, 2014). This proposal was approved by ASHA's board of directors in January 2014. McCrea (2014) attests that such training program is not yet available but that, "ASHA is committed to developing resources to enhance the training of supervisors" (p.8). Currently, supervisors can educate themselves about the supervisory process through continuing education, conferences, workshops, books, and the resources available on the ASHA website (O'Connor, 2008).

\section{Tasks of Supervision}

According to ASHA (1985), effective clinical teaching should result in "the development of self-analysis, self-evaluation, and problem solving skills on the part of the individual being supervised" (p. 3). ASHA (1985) has established and described 13 tasks of supervision along with their respective competencies. These tasks and competencies are deemed to be an important component of effective clinical teaching in speech language pathology. ASHA's (1985) 13 tasks of supervision indicate that a clinical supervisor's duties include: 
1. "Establishing and maintaining an effective working relationship with the supervisee.

2. Assisting the supervisee in developing clinical goals and objectives.

3. Assisting the supervisee in developing and refining assessment skills.

4. Assisting the supervisee in developing and refining clinical management skills.

5. Demonstrating for and participating with the supervisee in the clinical process.

6. Assisting the supervisee in observing and analyzing assessment and treatment sessions.

7. Assisting the supervisee in the development and maintenance of clinical and supervisory records.

8. Interacting with the supervisee in planning, executing, and analyzing supervisory conferences.

9. Assisting the supervisee in evaluation of clinical performance.

10. Assisting the supervisee in developing skills of verbal reporting, writing, and editing.

11. Sharing information regarding ethical, legal, regulatory, and reimbursement aspects of professional practice.

12. Modeling and facilitating professional conduct.

13. Demonstrating research skills in the clinical or supervisory processes" (ASHA, 1985, p.4). 


\section{Supervisor-Supervisee Relationship}

The supervisor-supervisee relationship is a significant topic of interest to many researchers in the field of communication sciences and disorders (Gillam, Strike Roussos, \& Anderson, 1990; Geller \& Foley, 2009; Kimble \& Turner, 2012; Osteregren, 2011; Pasupathy \& Bogscutz, 2013; Saras \& Post, 2008; Shapiro \& Anderson, 1989; Wagner \& Hess, 1997). Evidence has revealed that the quality of supervisor-supervisee relationships plays a critical role in the supervisees' clinical development and overall performance (Gillam, et. al 1990; Geller \& Foley, 2009; Shapiro \& Anderson, 1989; Pasupahty \& Bogschutz, 2013). Geller and Foley (2009) recommended a humanistic approach to supervision that takes into consideration the supervisee's behavior, affective states, interactions with others, and actions. The supervisory style and overall clinical experience, "may shape the future clinician's perception of his/her clinical success" (Kimble \& Turner, 2012, p.13). Therefore, it is important to determine which factors promote supportive clinical experiences for future clinicians. Supervisor-supervisee relationships may be positive, negative or neutral. Geller and Foley (2009) assert that positive relationships foster a sense of mutual trust, confidence, and empathy. As a result, this type of relationship will promote a working alliance with mutually-developed goals that benefits both the supervisor and supervisee.

\section{Early Research Studies}

Early research studies have found that supervisees' have demonstrated positive clinical behavior changes due to supervisor feedback in the form of written agreements, oral agreements and supervisor-supervisee data analysis. Specifically, Shapiro and Anderson (1989) studied the effectiveness of a written agreement between the supervisor 
and supervisee. This written agreement outlined a specific plan for the student clinicians to put into practice in order to improve his or her overall clinical development. The authors found that this method was successful in promoting positive clinical behavior changes in the student clinician; however, it was burdensome for the supervisor to develop and maintain. Therefore, it is not the most practical method of supervision to sustain over long periods of time.

Gillam and colleagues (1990) studied the effectiveness of a joint data analysis approach to supervision. This approach required the supervisor and the student clinician to collect data on the student clinician's behavior and analyze it together. The specific clinician behaviors targeted are: (a) explanations (i.e. "clinician utterances that concerned the procedures, outcomes, or intentions of an activity") (b) informative feedback (i.e. "any clinician utterance that followed a correct or incorrect client response and that contained an appropriate positive or negative evaluation plus a specific goal-oriented referent",) and (c) directive responses to off-task utterances (i.e. "the ability to bring clients back to a planned activity when they ventured off task") (Gillam et. al, 1990, p.55). Results from this study demonstrated that positive student clinician changes in the aforementioned target behaviors were noted only after the joint data analysis approach was implemented. This implies that student clinicians' target behaviors improved when they became the focus of supervision. Gillam et al. (1990) and Shapiro and Anderson (1989) both demonstrated the importance of supervisor feedback to more positive student clinician's performance and overall clinical skills development. 


\section{Recent Research on Supervisee-Supervisor Relationships}

A more recent study by Pasupahty and Bogschutz, (2013) revealed that speechlanguage pathology student clinicians' demonstrated a strong positive relationship between clinical self-efficacy beliefs and their clinical experience. Graduate students' clinical experiences are considerably influenced by the working relationship they have with their clinical supervisor. The clinical supervisor has the ability to foster a positive learning environment in which a student clinician is able to gain confidence in their growing knowledge and skill set. Pasupathy and Bogschutz (2013) refer to confidence in one's ability to perform a task using their knowledge and skill set as self-efficacy beliefs. These researchers also found that a more positive clinical experience is related to more positive clinical performance. A graduate student clinician's self-efficacy beliefs enable them to demonstrate more confidence in their ability to reason and carry out clinical tasks. This study illustrates the value of clinical practicum experiences for graduate student clinicians. Self-doubt and low confidence levels have the potential to undermine an individual's self-efficacy beliefs, even if they possess the knowledge and skill set to carry out clinical tasks (Bandura, 1982). Therefore, clinical practicum experiences can play a substantial role in shaping future clinicians beliefs, skills and professional practice.

Ostergren (2011) examined the experiences of first year speech language pathologists with their supervisors. In particular, she investigated the predominant role assumed by their supervisor, the working relationship between the supervisor and supervisee, and their satisfaction with supervision. Qualitative and quantitative data were collected on 122 participants. Results indicated that a majority of participants reported that their supervisors took on a collaborative or consultative role (Ostergren, 2011). 
Participants also identified what they considered to be the most important elements of the supervisor-supervisee working relationship. The top three elements identified were supervisors' expertise, supervisors' openness and approachability, and nature of supervisors' feedback (Ostergren, 2011). In addition, participants reported high levels of satisfaction with their supervision. In fact, there was a strong correlation between high levels of satisfaction with supervision and positive ratings of supervisor-supervisee working relationships (Ostergren, 2011).

Factors that constitute a positive supervisory experience were examined by Taylor, White, Kaplan, and O'Rourke (2012). They surveyed 23 graduate students and asked them to rank supervisor behaviors from most to least important. Results of this study demonstrated that graduate students valued the following attributes in a supervisor from most to least important: (1) knowledgeable (2) supportive, realistic, (3) realistic, (4) organized, (5) honest, (6) timely, (7) caring, (8) flexible, (8) patient, and (9) enthusiastic. Additionally, the researchers found that graduate students preferred receiving timely feedback in a written or face-to-face form. They also found that positive supervisory experiences were fostered when supervisors would create a collegial atmosphere that was conducive to the discussion of clients, therapy ideas, and goal formation (Taylor et al., 2012). When negative clinical experiences were reported by students, they expressed that the supervisor did not support the formation of a collegial relationship. The supervisor did not foster an open environment in which the student can freely discuss their own ideas for intervention. When students reported negative clinical experiences, they noted that the supervisors did not encourage formulation of their own intervention with the client, did not help the student to talk freely, and did not foster a collegial relationship 
(Taylor et al., 2012). It is important to note that the results from this study were acquired via responses to a survey. Thus, it is possible that open-ended questions and narratives could provide more information regarding the factors that constitute positive and negative clinical experiences.

\section{Effects of Negative Supervisory Experiences}

Although it is recognized that clinical practicum is critical to the therapeutic effectiveness of supervisees, many students still report negative supervisory experiences (Barrett \& Barber, 2005; Friedlander, Keller, Peca-Baker, \& Olk, 1986; Gray, Ladany, Walker, \& Ancis, 2001; Nelson \& Friedlander, 2001). Research has demonstrated that negative supervisory experiences have a detrimental impact on supervisees (Friedlander et al., 1986; Gray et al., 2001; Nelson \& Friedlander, 2001). A negative or harmful supervisory experience has been defined as, "supervisory practices that result in psychological, emotional, or physical harm or trauma to the supervisee" (Ellis, 2001, p. 402). Furthermore, this type of supervision can be characterized by "supervisor negligence, the supervisor acting inappropriately or with malice, or the supervisor clearly violating accepted ethical standards" (Ellis, 2001, p.402). Friedlander and colleagues (1986) interviewed supervisees who have had negative experiences and they reported feeling less competent and anxious. Fifteen years later, Nelson and Friedlander (2001) examined the same question with a different group of supervisees and they reported feeling distressed, exploited, and doubtful of their clinical abilities as a result of the negative supervisory experience. These findings are a result of studying supervisorsupervisee relationships in the field of psychology. Nevertheless, they are important and may apply to the field of speech-language pathology because a comparable dynamic 
exists. If the same type of negative or harmful supervision also exists, then it may have a similar detrimental impact on future clinicians in this field. Therefore, it is important to identify the characteristics of negative supervisor-supervisee relationships in order to reduce their presence in speech-language pathology.

\section{Qualitative Research Designs}

Qualitative research studies are beginning to be used more frequently in a variety of fields, ranging from psychology, linguistics, education, sociology and speech-language pathology (Chase, 2005; Ensslen, 2013; McComas, 2010; Yow, 2005). There are five primary analytical approaches to qualitative research: (1) narrative (2) grounded theory, (3) case study, (4) ethnography, (5) phenomenological (Creswell, 2007). Narrative inquiry approaches place a greater emphasis on an in-depth study of the life of an individual (Creswell, 2007). The purpose of the grounded theory approach is to develop a theory that is substantiated by the data collected (Creswell, 2007). Case studies seek to develop an in-depth understanding of a single individual or multiple cases (Creswell, 2007). Ethnographical research aims to describe the background and culture of an individual or group of people (Creswell, 2007). For the purposes of this research study, the phenomenological approach was selected. The phenomenological approach is a valuable form of inquiry in research in which the focus is on understanding and describing an experience or a lived phenomenon (Creswell, 2007). This approach allows for flexibility in the acquisition of information to better understand the clinical supervisory experiences of speech-language pathology graduate students.

Phenomenological research is often informed by the paradigm of constructivism. Constructivism assumes that, "through living in their world, [individuals] develop 
personal meanings of their experiences, and of objects and things in their environment" (Ensslen, 2013, p.51). Phenomenological research seeks to develop an understanding of these personal life experiences through open-ended questions and in-depth interviews. Through this theoretical framework, research is primarily dependent on the participant's own perspective and views of their personal experiences (Creswell, 2007). The inductive nature of this approach allows for a theory to develop as the study progresses, rather than imposing a pre-determined theory (Creswell, 2007; Ensslen, 2013; Lincoln \& Guba, 2000; Schwandt, 2001). The objective of this paradigm is to develop the most comprehensive knowledge of the phenomenon being examined. A phenomenological design was utilized for this study in order to describe individuals' clinical supervisory experiences and discover overall commonalities and themes among the different accounts (Ensslen, 2013; Moustakas, 1994; van Manen, 1990).

\section{Summary and Rationale}

It is widely recognized that clinical supervision is a significant component of the professional development for both supervisors and supervisees. For effective supervision to occur, the supervisor and supervisee must develop a positive working relationship founded in mutual trust and respect. ASHA (1985) has established and described 13 tasks of supervision along with their respective competencies which were deemed to be important for effective clinical teaching in speech language pathology. In 1988, Anderson proposed the continuum model of supervision which "mandates a change over time in the amount and type of involvement of both the supervisor and the supervisee in the supervisory process" (p. 14). In other words, supervision is a process which the supervisor is gradually decreasing his or her involvement in therapy sessions so as to 
encourage the supervisee to become more independent. This model outlines the goals of supervision; however, the specific factors of clinical supervision that result in positive and effective supervisor-student clinician relationship need to be further examined.

Knowing the descriptors of positive and negative supervision experiences is pivotal to promoting higher quality clinical training. Negative descriptors of supervisory experiences may help us minimize their occurrence in clinical practice. Thus, this study will be used to gain a better understanding of graduate students' perceptions, perspectives, and understanding regarding their clinical practicum supervisor experience. Student clinician feedback may help illuminate which particular supervisory methods enhance student clinician development and which methods suppress student clinical learning and involvement. This information is essential because the clinical practicum experience is a critical component of student clinician education since it can influence their overall professional development and success as a speech-language pathologist.

\section{Plan of Study and Experimental Research Questions}

This study will examine the characteristics of negative and positive supervisorsupervisee relationships through evaluation of the experiences of speech-language pathology graduate students in their clinical practicums. Participants will include graduate students currently enrolled in Florida International University's speech-language pathology master's degree program. Clinical practicum experiences will be studied using qualitative methods via participant interviews and open-ended questions. These data will be acquired using a phenomenological methodology approach. The focus of this analysis method will be to identify common themes among graduate student-supervisor clinical experiences. The following questions will be answered in-depth: (1) What are the most 
prominent descriptors of a positive supervisor-supervisee relationship? (2) What are the most prominent descriptors of a negative supervisor-supervisee relationship? 


\section{CHAPTER III}

\section{METHOD}

\section{Overview}

A phenomenological methodology approach was used to gain a better understanding of graduate students' perceptions, perspectives, and understanding regarding their clinical practicum experiences at Florida International University's speech-language pathology program located in Miami, FL. In-depth participant interviews were utilized to gather information about participant's clinical practicum experiences. The objective of this study was to determine the characteristics that define a positive or negative clinical supervisor-supervisee relationship. Phenomenological analysis influenced by constructivism was used to investigate and identify common themes among graduate student-supervisor relationships.

\section{Participants}

Participants were recruited via email and consisted of nine graduate students currently enrolled in Florida International University's speech-language pathology master's degree program. Participants met the following inclusion criteria: (1) be currently enrolled in a graduate speech-language pathology program, (2) have completed at least two clinical rotations (3) have experienced a positive or negative clinical supervisory experience. Of these participants, eight gave either a positive or negative narrative; however, one participant provided the researcher with a positive and negative narrative. Further demographic information and participant characteristics for this group can be found in Table 1. 


\section{Table 1}

Demographic Information

\begin{tabular}{lc}
\hline & $(n=9)$ \\
\hline Gender & 1 \\
Male & 8 \\
Female & \\
Race/Ethnicity & 5 \\
Hispanic & 1 \\
Black & 2 \\
White & 1 \\
Asian & \\
Age Range & 5 \\
$20-25$ & 3 \\
$26-30$ & 1 \\
$31-35$ &
\end{tabular}

\section{Procedure}

Following Institutional Review Board (IRB) approval, potential study participants were contacted via e-mail to inform them of the purpose of the study, the timeframe of the study, the inclusion criteria, and overall qualitative nature of the study. Interested graduate students were instructed to informally rate their clinical supervisory experiences as either positive or negative. Individuals who met the aforementioned inclusion criteria were considered for participation.

If the individuals met the inclusion criteria, students were contacted and given informed consent forms outlining full study information and confidentiality procedures. Participants were aware of the voluntary nature of the study. Upon returning the signed informed consent form, the researcher and participant scheduled a time to conduct the interview. Of the nine interviews, two were completed in-person, while the remaining 
seven were completed via Skype video call. It took approximately 30 to 45 minutes to conduct each interview. Each interview was recorded and transcribed by the researcher.

\section{Data Collection}

Due to the phenomenological nature of this study, the primary sources of data were in-depth semi-structured participant interviews. The semi-structured interview format grants the researcher the flexibility to change the sequence of the question and probe for more complete responses to maintain a conversation-like interview style (Creswell, 2007; Ensslen, 2013; Marshall \& Rossman, 2006; Merriam, 1998; Moustakas, 1994). After reviewing the relevant literature, the researcher developed a list of interview questions to be answered regarding participant's clinical practicum experiences. These questions were reviewed by the thesis committee members who are experienced with similar research methods.

Following a phenomenological design, two main open-ended questions were asked about the participants' experiences; as well as, six open-ended sub-questions (Creswell, 2007; Ensslen, 2013; Marshall \& Rossman, 2006; Merriam, 1998; Moustakas, 1994). The aim of these questions was to establish an understanding of the lived experiences of the participants. At the start of the interview, participants were informed:

"We are going to talk about your clinical supervisory experience. I encourage you to give as many examples and descriptions as you can." The researcher then asked the primary question of interest which was, "You mentioned you had a negative/positive supervisory experience. Why was that?" The second question of interest was, "How would you describe your working relationship with your supervisor?" The objective of these questions was to encourage the participant to describe his or her supervisory relationship 
and overall clinical practicum experience as fully as possible. A list of the complete interview sub-questions used can be found in Appendix A. Additional questions and probes such as: "Can you give me an example?" or "Tell me more about that" were used to elicit more information.

All the recorded interviews, transcripts, demographic forms, and informed consent forms were kept confidential. The identity of participants is known only to the researchers. All identifying information was removed from participants' documents and replaced with a unique participant number. The only documents with identifying information were the participants' signed informed consent forms which were maintained in a secure/locked location.

\section{Data Analysis}

Phenomenological data analysis approach was utilized to further examine the data with the goal of identifying the "essence" of the positive and negative supervisory experiences (Creswell, 2007). The "essence" of a phenomenological study can be defined as "what the participants experienced with the phenomenon and how they experienced it" (Creswell, 2007, p. 159). The first step is to acknowledge the researcher's own personal experiences with the phenomenon being studied. This is done in order to reduce the researcher's bias, although it cannot be eliminated in its entirety, and focus more on the participant's experiences of the phenomenon. Then, the researcher went through each interview transcript multiple times and developed a list of non-repetitive and nonoverlapping significant statements, sentences or quotes which captured participant's perception of their experiences. This step is known as horizontalization of the data (Creswell, 2007; Moustakas, 1994). Once this data was gathered, the researcher then 
grouped the statements into larger themes or "clusters of meaning" (Creswell, 2007, p. $61)$.

As a result, patterns and relationships in the data were discovered and used to categorize the significant statements, quotes and phrases within the participants' transcripts. Two principal themes were used to structure the data, ASHA's Task 1 of Supervision and Anderson's Continuum Model of Supervision. ASHA's Task 1 of Supervision was further subdivided into the specific competencies outlined under that task. By utilizing supporting statements, including quotes and phrases from the participants, the researcher then wrote a description of what the participants experienced with the phenomenon under study. This procedure is known as "textural description" (Creswell, 2007, p. 159). The next step was to complete a "structural description" (Creswell, 2007, p. 159). This entailed writing a possible explanation which described how the participants' experiences of the phenomenon being studied may have been impacted by the context or setting in which the experience occurred. Essentially, this procedure is used to understand how the context or setting influenced the overall experience of the participant. These textural and structural descriptions were then used to represent the "essence" of the experience that was shared by all of the participants. This final step focused on "what the participants experienced with the phenomenon and how they experienced it" (Creswell, 2007, p. 159). This description highlights the shared experiences of the participants and attempts to facilitate the readers understanding of positive and negative supervisory experiences for graduate students in the field of speech language pathology. 


\section{CHAPTER IV}

\section{RESULTS}

The results of this research study are presented in this chapter and are organized according to two principal themes: ASHA's Task 1 of Supervision and Anderson's Continuum Model of Supervision. Participants' perspectives of positive and negative supervisory experiences as supported by participants' direct quotes, statements, and phrases are categorized according to this structure. ASHA's Task 1 of Supervision has been further sub-divided according to specific competencies as outlined by ASHA (1985). Related competencies have been grouped together to facilitate the discussion of related phenomenon that the participants' have experienced. A descriptive narrative of the two principal themes and subthemes have been developed and supported by the use of direct quotes from the participants' interviews. These narratives are intended to provide the reader with a better understanding of the phenomenon under investigation and to illuminate and reconstruct the lived experiences of the participants.

The subthemes of ASHA's Task 1 of Supervision were divided as follows:

a. Competency 1.1 and 1.9 respectively: "Ability to facilitate an understanding of the clinical and supervisory processes" and "ability to establish joint communications regarding expectations and responsibilities in the clinical and supervisory processes"

b. Competency 1.3, 1.5, and 1.8 respectively: "Ability to interact from a contemporary perspective with the supervisee in both the clinical and supervisory process"; "Ability to apply skills of interpersonal communication in the supervisory process"; "Ability to interact with the supervisee objectively" 
c. Competency 1.4: "Ability to apply learning principles in the supervisory process"

d. Competency 1.7: "Ability to maintain a professional and supportive relationship that allows supervisor and supervisee growth" (ASHA, 1985, p.4).

\section{Theme One: ASHA's Task 1 of Supervision}

ASHA (1985) has established 13 tasks for supervision along with their respective competencies. Upon examination of the data, a majority of the significant statements regarding positive or negative supervisory experiences primarily address ASHA's Task 1 of Supervision: "Establishing and maintaining an effective working relationship with the supervisee" (ASHA, 1985, p.4). Among the nine participants, this task of supervision was addressed in various manners throughout the participants' interviews. In order to more deeply discuss and describe this overlaying theme, the sub-competencies will be examined individually. A brief description of the competencies is provided, followed by supporting participant statements from the positive supervisory experience group and then the negative supervisory experience group. The intention is to identify and describe the positive and negative characteristics as perceived by speech language pathology graduate students.

\section{Competency $1.1 \& 1.9$}

These two competencies focus primarily on the supervisor's, "ability to facilitate an understanding of the clinical and supervisory processes" and "ability to establish joint communications regarding expectations and responsibilities in the clinical and supervisory processes" (ASHA, 1985, p.4). Participants' interviews indicate that they valued knowing what supervisors' expected from them and what their responsibilities 
would entail with the clinical and supervisory processes. Discussion of these competencies will be organized by examining significant participant statements from the positive supervisory experience group and then the negative supervisory experience group.

\section{Positive Supervisory Experiences}

Four out of the five study participants within the positive supervisory experience group discussed the importance of having a clear understanding of their supervisor's expectations. Participant 2 indicated that, "During the initial interview, she gave me a handout which outlines everything she expected from me. She gave me specific dates of when things were due. All her expectations and everything really were very clear and straightforward." Below is a list of similar supporting direct quotes from the participants' interviews:

a. Participant 3: "...my first supervisor took the time to really explain what SLPs do in the profession, particularly, what's expected of us in evaluations and therapy. She just took the time to explain all the rules of the clinic and what was really expected of me.”

b. Participant 3: "She was always clear on her expectations and what she wanted to see me improve upon."

c. Participant 7: "Before I started my rotation, we had an interview and during that interview she told me what my job duties would be. She specified what it is she wanted to be to do." 
d. Participant 9: "She made it clear from the beginning that I would start on my own and she would step in to help me if I needed it. She made that very clear. Exactly how she said it would be was how it was."

In their interview responses, these four study participants emphasized the importance of a supervisor who is "clear" and "straightforward" in discussing their clinical expectations and responsibilities. These participants valued a supervisor who would take the time to specify their roles and facilitate their overall understanding of the clinical and supervisory process. When a supervisor did this, students were more likely to identify the supervisory experience as a positive one.

\section{Negative Supervisory Experiences}

When a supervisor did not clearly specify the responsibilities, roles and expectations of the graduate student within the clinical and supervisory process, participants were more likely to perceive the supervisory experience negatively. Recalling the experience, Participant 8 remarked, "So I would say that in the beginning, I had these expectations based off what she told me but it all changed. I didn't know what to expect anymore. I would have anxiety just going into the clinic. I never had anxiety in my life and it started that semester." This participant's experience indicates that not knowing her supervisor's expectations of her was distressing and a cause of anxiety for her. She also noted that her supervisor, “...would always come in late to work and I wasn't sure if I could start therapy without her there." Overall, her experience with her supervisor was full of uncertainty which stemmed from the lack of clarity regarding her supervisor's expectations for her as a graduate student clinician. 
Three other study participants also commented on the lack of clarity regarding their supervisor's expectations; however, they did not appear to be as impacted by it as Participant 8 was. Below are the other three participants' comments regarding this topic:

a. Participant 4: "She wasn't very clear about her expectations but I basically took over her schedule and we didn't have very difficult cases or anything so she rarely intruded."

b. Participant 5: "She just told me what the clinic was about and what kind of clients they saw but aside from that she never really talked about her expectations. She wasn't very clear on that. And I wasn't really sure what my role was as a student clinician."

c. Participant 6: “He was never clear. He didn't even seem to know what was supposed to happen. He never told me what was expected of me. ... when I would ask him questions, he really wouldn't have an answer. So it all felt unclear. It was hard. It was really hard.”

Collectively, these four participants who reported having a negative clinical supervisory experience also reported that they had supervisors who were not "clear" regarding their expectations within the clinical and supervisory process.

Competency $1.3,1.5, \& 1.8$

These three competencies within ASHA's Task 1 of Supervision address a supervisors, "ability to interact from a contemporary perspective with the supervisee in both the clinical and supervisory process", "ability to apply skills of interpersonal communication in the supervisory process", and "ability to interact with the supervisee 
objectively" (ASHA, 1985 p.4). Direct quotes from participants' interviews indicate that participants valued a supervisor who demonstrates understanding, respect and trustworthiness. The participants' perception of their' day to day interactions with their supervisors differed between the two groups of participants. These perceptions will be presented first with the positive supervisory experience group and then the negative supervisory experience group.

\section{Positive Supervisory Experiences}

All five participants in this group described various aspects of their interactions with their supervisor which they perceived to be positive. Data from the participants' interviews indicated that they valued supervisors who made them feel "valued", "respected" and "comfortable". Participants' also responded well to a supervisor who is available, encouraging, and approachable. Participant 3 explained that her supervisor made her "...feel comfortable and very welcomed. During my time at the clinic, I felt like I was part of the team. She really took the time and made me feel valued. There weren't many times where I felt like I couldn't do something. She was always positive and encouraged me to try new techniques."

POSITIVE STATEMENTS:

a. Participant 2: "She respected me but also taught me so much."

b. Participant 3: "I felt like she valued and respected me."

c. Participant 10: "I felt like she valued my opinion and throughout the session, I could ask her questions." 
d. Participant 2: "She made me feel at ease and at home. She made me feel like I wasn't working for her but working with her. I always felt comfortable and I was able to voice my opinions."

e. Participant 7: "I enjoyed working with her. I was always following her around. I felt comfortable around her and felt like I could say anything."

f. Participant 9: "She always made room, no matter how busy she was, to address all my questions. She always made it seem like she was available for me even when she was very busy."

\section{Negative Supervisory Experiences}

Every participant in the negative supervisory experience group discussed their perception of their supervisor's limitations in communicating and interacting with them. Participants' were likely to describe their interactions with these supervisors as, "uncomfortable", "not trustworthy", “condescending" and "rude". Participant 6 explained, "I could never openly talk to him. It was more so because I felt like he was not trustworthy because I found out he was telling lies about me to his supervisor.

Eventually, she found out what was going on and she didn't hold me accountable for certain things. She told me that she could see what type of person I was and she saw that I was a hard worker. So eventually, she knew that he wasn't being truthful and held him accountable". This participant further expressed that, "It was an uncomfortable situation to be in". Supervisory interactions which lack trust between the supervisor and supervisee were more likely to be characterized as negative. Other participants describe situations in which their supervisors made inappropriate comments and demonstrated overall negative 
affect, body language and tonality in their interactions with their supervisees. Below is a list of negative comments:

a. Participant 1: "I don't know if I mentioned this but she made me cry at least twice in person in front of her which is completely humiliating. It was because she yelled at me and she caught me off guard completely. I've never had a teacher yell at me like that before. It was embarrassing. "

b. Participant 1: "Whenever I would present my plan, she would be so rude with her body language. She would have her arms crossed, legs crossed, shoulders slumped and would give me this face as if listening to me was a complete waste of her time. She would look at me with her mouth open and eyes squinted. She had this body language and attitude from my first day."

c. Participant 1: she would always yell at me, 'I can't believe that you can't get the note done. I can't believe you. You are not doing it right. I don't understand why you're not getting it. I just can't believe you don't get it.' I don't know if I'm conveying how mean and rude her tone was, she was so condescending, angry and aggressive in her tone.

d. Participant 4: "She would just add anyone to the schedule and never really took into account that I was the one doing the therapy and I wouldn't have time to prepare. I feel like she never took me into consideration."

e. Participant 5: "For whatever reason, she decided to critique my appearance and she really went at it. I feel like she went too far. She criticized the way my hair was done that specific day to my blemishes. 
She had felt the need to address that. I did dress professionally and I would show up on time but she just didn't like my appearance. I can't change that. She said my personality was also an issue. I feel like with the midterm, she wasn't focusing on my work."

f. Participant 5: "She even gave me beauty tips which I thought was very inappropriate. I remember her telling me that she was impressed with how well I was taking this feedback because if it were her she would be talking back. But honestly, I felt like all I could do was be quiet and take it.”

g. Participant 8: "She would speak to me in a very negative tone, it was very condescending. That would make me very nervous and honestly, just being around her started making me nervous. She would talk to me in a bad way."

h. Participant 8: “Her treatment would make me nervous. If she didn't like something, she would give me a mean face and give me attitude. She would roll her eyes or squint them when she wasn't happy with me. She even would yell at me and that made me anxious. Any little concern I had, if it was against her way then she would make me feel bad for it. It made me feel uncomfortable. Just coming into the clinic, I would feel anxious."

\section{Competency 1.4}

This competency within ASHA's Task 1 of Supervision addresses a supervisor's, "ability to apply learning principles in the supervisory process" (ASHA, 1985 p.4). Participants strongly valued a supervisor who is able to provide them with mentorship 
and effective feedback. These clinical experiences were more likely to be perceived as positive by the study participants.

\section{Positive Supervisory Experiences}

Study participants' expressed that they enjoyed being challenged to excel and learn more in their clinical practicum experiences. Participant 9 asserted, "I like that she always challenged me. I think that was one of my favorite things about her. She never made it easy for me." When asked to elaborate on how her supervisor would challenge her, Participant 9 explained, "For instance, I would ask her a question during my therapy session and she would come in and help me. But she wouldn't leave it at that. She would come at the end of the day, give me handouts and a list of different topics for me to research in regards to whatever question I asked her. She would assign me that and I would have to come at the end of the week with information about different things that I learned about that certain topic. She did it to help me and further challenge me." This statement indicates that students learn more when supervisors take the time and acknowledge students' questions. This illustrates that supervisors do not necessarily need to answer the question for the student to benefit from this interaction. Other participants describe different situations in which they learned during their clinical practicum experiences:

a. Participant 2: "She took the time during a patient's slot to teach me the Beckman Oral Motor. Any chance we would get, we would review and she would give me handouts on the technique. She really took the time to teach me."

b. Participant 2: "She even helped me learn to talk to parents. She gave me pointers on how to approach it and what I should change in my approach. “ 
c. Participant 3: "There was one situation in which we had this very challenging patient. He was really hard to work with in the beginning. But I kept trying and she kept giving me direction and telling me what we could do to help him grow. If I needed help, she would show me what I could do with him.”

d. Participant 7: "The supervisor I had was very informative and always helpful. She gave me many opportunities to ask questions. I never felt intimidated or worried about asking questions with her which is really important."

e. Participant 7: "She really took the time to teach me and explain what was happening."

f. Participant 9: "During the interview she told me that I was going to learn through application and that she wanted me to treat that clinical site as a lab. She wanted me to apply everything I was learning in the textbook. She said she would be there with me while I was seeing patients but she really wanted me to learn through application."

A supervisor who is able to provide effective feedback was also deemed as an important positive characteristic across all study participants within this group:

a. Participant 2: "My supervisor provided constant feedback the entire time I was there."

b. Participant 2: "She would take an hour if she needed to talk to me and explain what she thought I could improve upon. She made it a point to give me feedback and show me all the corrections. Once she did that a few times, she would let me correct myself." 
c. Participant 3: "She also gave me lots of feedback throughout the rotation, so I felt like I had a lot of support. ... she gave me lots of positive praise. She would tell me what I did right and which areas I can improve on."

d. Participant 3: "She would give me one-on-one advice and feedback all the time. When I was treating a patient, she would tell me specifically what I could improve upon; as well as, what things I did great.”

e. Participant 3: “...she took the time and told me that I did an excellent job. She even took the time to tell her boss about how great I did. It really made me feel like part of the team and welcomed. It was a very positive experience for me and it's still one that I carry with me today."

f. Participant 7: "She also provided me with great feedback all the time. When I had a therapy session, she would tell me what I did right. She would always tell me what I did right and then she would tell me what I missed. She also gave me advice as to what I can do as a future clinician. She provided me with a lot of insight and I felt like I learned so much at that site."

g. Participant 7: "When I did the therapy session, there would be a two-way window so she would be watching me from the other side because she didn't like to interrupt me. Once the session was over, we would talk about how it went. I would usually get immediate feedback after each session."

h. Participant 9: "She was very helpful and gave me lots of feedback." 
i. Participant 9: "She would always observe and help me out. She would correct me but in a nice way. She would address it after my therapy session or she would step in and show me what she wants me to do."

\section{Negative Supervisory Experiences}

One participant from this group acknowledged that although her internship was "very intense" she was able to learn from her supervisor. She stated, "Aside from all the negative stuff that happened, I did learn a lot from her. It was just very intense. I did learn a lot of behavior modification strategies from her. It was tough and unfortunately, I felt like it could have been better. But I did learn.” However, four out of five study participants within this group reported that they did not feel like their supervisor advanced their knowledge in the field of speech language pathology. Some negative comments include:

a. Participant 1: "As a supervisor, part of her job is supposed to be teaching. During her interactions with interns, many times her tone of voice came across as angry, frustrated and often condescending. Eventually, I just stopped asking questions because I just didn't want to frustrate her and this is especially not conducive to learning."

b. Participant 4: "I feel like she wasn't teaching me. She would sit there but she would be on Facebook or she would be buying things on Amazon or something."

c. Participant 4: "Even if she saw me struggling with a patient, she wouldn't do anything. I feel like she didn’t teach me. “

d. Participant 4: "I'm not so sure about what she taught me but I did learn from the site. I learned a lot from the kids I worked with because at the time I 
never worked with autism. But in regards to what she taught, it was definitely not much. I felt like I was the one sharing information. So I didn't really learn anything from her."

e. Participant 5: "For me coming into the internship, I was hoping for more mentorship and guidance."

f. Participant 5: “She also didn't like when I would ask questions, even when I was really stuck and needed the help."

g. Participant 6: "I feel like I did get information from that rotation but it wasn't really from him. I would have learned so much more if he took the time to give me feedback. I wish I had a supervisor that wanted to teach. I feel like I could have learned more. I feel like he hindered my growth as far as learning about the adult area. I had to figure it all out on my own through Google."

h. Participant 6: "I didn't feel like he wanted to teach me. He didn't teach me. He made his way around that. It wasn't a good experience and it made the whole situation dreadful and that was hard. I didn't want to get up and go to work just to be in that situation. I would dread it the whole time. It took so much energy."

All participants within this group reported that they felt like they lacked effective and constructive feedback from their supervisors. Some of those comments include:

a. Participant 1: "Whenever I came up with something completely new, she would say things like, 'Oh, do you think that's appropriate for this kid?' She would always give feedback like that. And that's how I knew it wasn't 
appropriate because she would basically be rude. I knew she didn't like it but she would never tell me why. Even when I asked. So I gave up. “

b. Participant 1: "It was incredibly frustrating because she only focuses on the negatives and never acknowledges my strengths."

c. Participant 4: "Her feedback was minimal and always delayed. [...] She never would talk about my technique or how I targeted a goal."

d. Participant 4: "The feedback wasn't about the actual note itself but the typos or grammar. It just wasn't effective.”

e. Participant 4: "I rarely got feedback from her. We didn't really have good communication between us."

f. Participant 5: "I have felt that her feedback wasn't really constructive. It just felt like criticism versus constructive criticism. It was always negative. She would say, 'You're not doing this right'..'

g. Participant 5: "One time she mentioned that what I did with a client was completely inappropriate but she never told me which client or what I did.

So that wasn't useful."

h. Participant 6: "What made it most challenging is he didn't give me any feedback or critique on my sessions. I would have dealt with being overworked if he had just given me feedback. I would have felt like I had something to take away from the clinic. I feel like I couldn't take anything away as far as him teaching me. It was more of what I learned on my own there. I just had to figure things out for myself." 
i. Participant 8: "Even if I would ask her for help, she would yell across the hallway but she wouldn't come to help or observe me. I would be stuck in the room not knowing what to do. I would talk to her afterwards and ask her if she could observe me next time and give me tips on what I could improve upon. And she would make me feel bad for asking."

\section{Competency 1.7}

This competency emphasizes a supervisor's, “ability to maintain a professional and supportive relationship that allows supervisor and supervisee growth" (ASHA, 1985 p.4).

\section{Positive Supervisory Experience}

All five participants within this group discussed how their supervisors were supportive, encouraging and facilitated their overall growth as a clinician. Reflecting on her supervisory experience, Participant 10 remarked, "At first this will sound like a negative but she told me, 'I don't see you as a therapist right now.' But I felt that too so I took it as a positive. [...] But as time went on, she told me that I made tremendous growth and she sees me more as a therapist. She even asked the other supervisors if they've seen the growth I've made in the clinic. They said no and so she actually took a video recording of me to show them my progress. So I really appreciated the fact that she did that." Her experience illustrates an instance in which a supervisor not only acknowledged growth in a student's clinical abilities but also took the time to video record her and share it so that others could witness it too. Some positive participant comments include:

a. Participant 2: "She made me feel competent. She was very supportive." 
b. Participant 2: "I taught her a couple of things that I learned and she taught me new techniques as well. We were able to learn from each other. I think it benefitted that patient to have both of us co-treating that patient."

c. Participant 3: "She would tell me if I wanted to take notes on certain things that I can improve on and then we would look back at them and measure my improvement."

d. Participant 3: "She was always positive and encouraged me to try new techniques.

e. Participant 7: "She was very supportive and facilitated my growth as a clinician. She was always there. She was always ready to answer my questions. She never made me feel bad for not knowing something."

f. Participant 9: I felt that it's one thing learning at school but once you're out there in the clinical site, you need a supervisor that is actually willing to help you grow. It makes such a difference. You learn so much more that way. I felt like I learned a lot through application and she was very supportive of that.

\section{Negative Supervisory Experiences}

Study participants within this group describe perceived supervisor deficits in regards to their, "ability to maintain a professional and supportive relationship that allows supervisor and supervisee growth" (ASHA, 1985 p.4). Some negative comments include:

a. Participant 1: "She made me feel like she was judging me the whole time. Especially with the things she would say like, 'I can't believe you don't get that', 'I can't believe you don't do this', 'I can't believe you don't 
know that' 'Don't you understand?'. I would hear that all the time, every day. I couldn't help but doubt myself. Whenever she would say those things, I would ask her to clarify and be more specific as to what she meant. But she would get all exasperated and tell me to just do whatever I wanted. But her frustrated tone and body language would tell me otherwise."

b. Participant 4: "For instance, I would be targeting a goal wrong. But she would watch my videos at the end of the week. So if I made a mistake, if she was actually supervising me, she could tell me right away and it would only happen one time. But since she waits, it would be an entire week in which I was doing something wrong. And she would get really mad at me for consistently making that mistake. But I had no way of knowing I was wrong until she told me at the end of the week. It was frustrating. I just didn't know."

c. Participant 5: "Most of her critique wasn't even about the actual job at hand. I looked at the midterm grade and addressed those areas that she thought were weak. But outside of that, I tried to ignore her comments about my appearance or comments that were not about my actual work. I feel like I did improve despite the lack of mentorship, guidance and support I got. I pulled through.”

d. Participant 6: "He gave me my whole schedule for the entire semester. So he would switch weekends and I would have a group project to do. He wouldn't care. He would tell me a day before that I have to work the next 
day. I would tell him I already planned a group project and he would tell me, 'Clinic is important.' I knew that but I had the schedule from before and planned it when I knew I had the day off. He would always say "clinic is important". That was his response to everything. He would always be upset if I had to leave for a school project or class. It made the situation uncomfortable because he would always seem so upset when I would have to leave just an hour early. I struggled very badly with my academics last semester."

e. Participant 8: "She would make a lot of negative comments about another intern there and I did not like that at all. I didn't think it was appropriate or professional. It made me feel like I didn't want to be there."

\section{Theme Two: Anderson's Continuum Model of Supervision}

As indicated, Jean Anderson proposed a model of supervision in 1988. This is now one of the most prominent models in the field of speech-language pathology, known as the continuum model. Anderson (1988) expressed that supervision should exist on a continuum and thereby it, "mandates a change over time in the amount and type of involvement of both the supervisor and the supervisee in the supervisory process" (p. 14). According to this model, the supervisor is gradually decreasing his or her involvement in therapy sessions so that the supervisee can learn to become more independent. A majority of study participant who reported a positive supervisory experience also reported supervisory approaches that correspond with Anderson's Continuum Model of Supervision. 


\section{Positive Supervisory Experiences}

Three of the five participants within this group described a supervisory relationship that is consistent with Anderson's Continuum Model of Supervision. These participants valued a supervisor who was skilled in transitioning them based on their skill level within the clinical setting. Some positive comments include:

a. Participant 2: "In the beginning, she was with me in the room, she would jump in during the middle of the session if she saw that I needed her help. I would incorporate her suggestion and overall, it was very smooth. Towards the end of the internship, she would step out and observe outside the door. During that time, she would wait and give me feedback after. She wanted to see if I could learn to fend for myself. So at the beginning of internship she would be involved in the session and jump in when I needed her. But towards the end, she let me do most of the treatment and provide her feedback at the end of the session. That really worked well for me."

b. Participant 3: "As I became more experienced, I got less and less feedback. I felt that I had more control as time went on. She lessened her control because in the beginning she was very hands-on with me. She was always showing me how to do things and towards the end she let me take control. I could tell that she trusted me. I liked that she would let me rule the show."

c. Participant 10: "So it began with observations at first and then co-treating and then she allowed me to be more independent and transition more in and lead the session. If I had any problems, she would jump in on occasion. This 
was towards the beginning of the rotation. Towards the middle, she did mention that she wanted to see how I would do more independently."

\section{Negative Supervisory Experiences}

Conversely, four out of five participants who reported a negative supervisory experience described a supervisory style which contradicts Anderson's Continuum Model of Supervision. These supervisors were perceived to be "passive" and "absent" throughout the clinical and supervisory process. Some negative comments include:

a. Participant 4: "I basically took over her schedule the first week. After I did that, she let me take over and didn't do anything. She played a very passive role. She may as well not have been there."

b. Participant 5: "Typically, I would see the client and she would observe me. It was very rare that we would co-treat or give me advice. She was more of a passive observer. I actually had to ask her to co-treat in the beginning and I felt like she got frustrated with me for that. Overall, it felt like she was frustrated with my lack of experience."

c. Participant 6: "With this rotation, I did not get feedback the entire time. From the time we started to the time we finished, there was never a session in which he told me what I could have done differently or what I needed to improve on. I feel like I needed that because it was my first time working with adults. I'm here to learn and I feel like I didn't get that experience."

d. Participant 6: "To be working 40 hours a week, doing all the sessions myself with an absent supervisor was really hard." 
e. Participant 8: "Ok well to begin with, I think it was because of the fact that she would throw everything on top of me and expect me to do everything from day 1. It was my first rotation and I feel like she was expecting a lot. She would always come in late to work and I wasn't sure if I could start therapy without her there. I took over her full caseload within the week."

These findings suggest that student clinicians negatively perceived their clinical experiences when they had a supervisor who was "passive" and "absent". Many of these participants fully took over the caseload within the first week of their first clinical rotation. This demonstrates that their supervisors were not skilled in transitioning them according to their skill level. These supervisory experiences directly contradict Anderson's Continuum Model of Supervision. 


\section{CHAPTER V}

\section{DISCUSSION}

The purpose of this study was to gain a better understanding of the factors that constitute a positive and negative supervisor-student clinician relationship as perceived by graduate students. Recorded in-depth interviews with a preplanned script were used to elicit descriptions from participants regarding their supervisory experiences. Data were collected via recorded in-person or Skype video calls. After the data were collected and transcribed the narratives were analyzed to draw useful inferences and discover underlying themes. Two overlaying themes, ASHA's Task 1 of Supervision and Anderson's Continuum Model of Supervision, were identified from the participants' interviews and they were used to categorize the data.

Overall, results indicate the most likely factors attributed to a positive clinical experience included constructive feedback, respect, positive praise, clear expectations and structured clinical guidance while the factors that were most likely attributed to a negative experience were lack of constructive feedback, negative criticism, and minimal clinical guidance. Additionally, participants who reported a positive clinical experience also described a model of supervision which closely corresponds to Anderson's Continuum Model in which they felt they had a supervisor who skillfully transitioned them according to their developing clinical knowledge and ability. Conversely, those who reported a negative supervisory experience described a more passive model of supervision characterized by an "absent" supervisor who they perceived was unable to provide them with the support they needed to grow as a clinician. 


\section{Theme One: ASHA's Task 1 of Supervision}

Results of this study revealed that ASHA's Task 1 of Supervision which states that a supervisor should be skilled in, "establishing and maintaining an effective working relationship with the supervisee" (ASHA, 1985, p.4), is an integral aspect in determining the speech language pathology graduate students' perception of their overall clinical supervisory experiences. Data from the study participants' interviews indicated that the following sub-competencies of this task were deemed as important:

a. Competency 1.1 and 1.9 respectively: "Ability to facilitate an understanding of the clinical and supervisory processes" and "ability to establish joint communications regarding expectations and responsibilities in the clinical and supervisory processes"

b. Competency 1.3, 1.5, and 1.8 respectively: "Ability to interact from a contemporary perspective with the supervisee in both the clinical and supervisory process"; “Ability to apply skills of interpersonal communication in the supervisory process"; "Ability to interact with the supervisee objectively"

c. Competency 1.4: "Ability to apply learning principles in the supervisory process"

d. Competency 1.7: "Ability to maintain a professional and supportive relationship that allows supervisor and supervisee growth" (ASHA, 1985, p.4).

\section{Competency $1.1 \& 1.9$}

According to Ensslen (2013), "When graduate students are aware of what is expected of them in the clinical setting, they may be able to better gauge their supervisors' personal expectations"(p. 105). Supporting quotes from participants' 
interviews indicate that they valued knowing what supervisors' expectation, as well as, what their supervisee responsibilities would entail within the clinical and supervisory processes. Students were more likely to identify the supervisory experience as a positive one, when they had a supervisor who specified their roles, was "clear" and "straightforward" and facilitated their overall understanding of the clinical and supervisory process. Supervisors who did not overtly specify the responsibilities, roles and expectations of the graduate students, were more likely to be perceived negatively.

This lack of clarity even proved to be a source of anxiety for some study participants. Participant 8 explained, "So I would say that in the beginning, I had these expectations based off what she told me but it all changed. I didn't know what to expect anymore. I would have anxiety just going into the clinic. I never had anxiety in my life and it started that semester." Friedlander and colleagues (1986) also found this to be the case when they interviewed supervisees who have had negative supervisory experiences. Their participants reported feeling less competent and anxious during their clinical practicum (Friedlander et al., 1986).

\section{Competency 1.3, 1.5 , and 1.8}

Supporting statements from the study participants' interviews suggested that participants valued a supervisor who respects them and who they perceive to be trustworthy. Every participant within the positive supervisory experience group expressed how their supervisors made them feel comfortable, valued, and respected. Similarly, Geller and Foley's (2009) findings assert that positive supervisory relationships foster a sense of mutual trust, confidence, and empathy between the supervisor and supervisee. This encourages a supportive relationship and comradery. A 
few participants even remarked that they felt like they were part of the team. Participant 3 explained, "During my time at the clinic, I felt like I was part of the team. She really took the time and made me feel valued. There weren't many times where I felt like I couldn't do something." This type of relationship encouraged students to learn and attempt new therapeutic techniques. These supervisory interactions only enhance graduate student's clinical knowledge and skills.

Conversely, participants in the negative supervisory experience group described their interactions with their supervisors as "uncomfortable". Many times, these participants perceived their supervisors as being "condescending" and "rude". Reports from the participants suggest that tonality, affect and overall body language play a significant role in whether or not an interaction is perceived to be positive or negative.

\section{Competency 1.4}

It has been established that receiving constructive feedback, verbal or written, is an important aspect of clinical and supervisory process for graduate students (Ensslen, 2013; Gillam et. al, 1990; Ostergren, 2011; Shapiro \& Anderson, 1989; Taylor et al., 2012). Research studies have demonstrated the importance of supervisor feedback to more positive student clinician's performance and overall clinical skills development (Gillam et. al, 1990; Ostergren, 2011; Shapiro \& Anderson, 1989; Taylor et al., 2012). Accordingly, within this study, participants were more likely to perceive their experience as positive one if their supervisor provided them with effective feedback and mentorship. Moreover, supervisors who take the time to teach and acknowledge students' questions were strongly valued by the participants. Additionally, data suggests that students also liked being challenged to excel and learn more in their clinical practicum experiences. Every 
study participant also expressed that the importance of effective positive feedback and constructive criticism. Study participants within the negative supervisory group reported that they did not feel like their supervisor advanced their knowledge in the field of speech language pathology. Additionally, they perceived that their supervisor provided them with excessive criticism; however, it was rarely positive or constructive. Participant 1 noted, "It was incredibly frustrating because she only focuses on the negatives and never acknowledges my strengths."

\section{Competency 1.7}

Pasupathy and Bogschutz (2013) found that a clinical supervisor has the ability to foster a positive learning environment in which a student clinician is able to gain confidence in their growing knowledge and skill set. This promotes a supervisee's selfefficacy beliefs or confidence in one's ability to perform a task using their knowledge and skill set (Bandura, 1982; Pasupathy \& Bogschutz, 2013). Every participant within this group discussed the manner in which their supervisor either facilitated or hindered their overall growth as a clinician. Participants valued a supportive and encouraging supervisor. According to Bandura (1982), encouragement or "social persuasions" can impact an individual sense of self-efficacy. There are two types of social persuasions, positive and negative, respectively, one increases self-efficacy, whereas, the other decreases self-efficacy. This indicates that a supervisor who is able to maintain a positive and supportive relationship with supervisee can help them grow in their overall confidence in their clinical ability. As a result, the supervisee's performance is also expected to improve, as well as, their perception of themselves as future clinicians. 


\section{Theme Two: Anderson's Continuum Model of Supervision}

Three of the five participants within the positive supervisory experience group described a supervisory relationship that reflects Anderson's Continuum Model of Supervision. They expressed that their supervisors were skilled in transitioning them according to their skill level within the clinical process. If a student's clinical abilities are not sufficiently established to handle the clinical situations they are faced with, then they are likely to struggle and experience difficulty developing clinical competence (Schon, 1987). Accordingly, four out of five participants who reported a negative supervisory experience described situations in which their supervisors did not transition them according to their skill level. These supervisors were perceived to be "passive" and "absent", and therefore, they did not support the students in moving along the continuum of clinical competence.

\section{Limitations of the Study}

This current study utilized a phenomenological design with the objective of expanding the understanding of the positive and negative clinical supervisory experiences from the student clinician's perspective. No data was collected from the supervisors. It is also important to note that this study consisted of a sample size of nine. One participant provided a narrative regarding her positive and negative supervisory experience.

Additionally, the participants consisted of graduate students enrolled in one Master's of Science in Speech-Language Pathology program. In order to better generalize these results to the larger population, more students should be interviewed from a variety of university programs. 


\section{Implications for Future Studies}

The findings from this study can be used as a guide for future research studies with similar research questions regarding supervisor-supervisee relationships in the field of speech language pathology. Results from this study attempt to provide a general explanation of the phenomenon being studied from the student clinicians' perspective. Future research studies could gather data from both student clinicians and supervisors in order to more holistically understand the complexity of the supervisor-supervisee dynamic.

\section{Summary and Conclusions}

Two overlaying themes, ASHA's Task 1 of Supervision and Anderson's Continuum Model were identified from the data collected from the participants' interviews. Overall, results indicated that most likely factors which attributed to a positive clinical experience as perceived by graduate students included constructive feedback, respect, positive praise, clear expectations and structured clinical guidance. Conversely, the factors that were most likely attributed to a negative experience were lack of constructive feedback, negative criticism, and minimal clinical guidance. Additionally, participants who reported a positive clinical experience also described a model of supervision which closely corresponds to Anderson's Continuum Model in which they felt that they had a supervisor who skillfully transitioned them according to their developing clinical knowledge and ability. 


\section{References}

American Speech-Language-Hearing Association. (1985). Clinical Supervision in Speech-Language Pathology and Audiology [Position Statement]. Available from www.asha.org/policy.

American Speech-Language Hearing Association (2008) Clinical supervision in speech language pathology (Position statement). Retrieved from http://www.asha.org/policy/PS2008-00295.htm

Anderson, J. (1988). The supervisory process in speech-language pathology and audiology. Boston: College Hill Publication.

Bandura, A. (1982). Self-efficacy mechanism in human agency. American Psychologist, 37, 122-147.

Barrett, M. S., \& Barber, J. P. (2005). A Developmental Approach to the Supervision of Therapists in Training. Journal of Contemporary Psychotherapy, 35(2), 169-183. doi:10.1007/s10879-005-2698-8

Chase, S. E. (2005). Narrative inquiry: Multiple lenses, approaches, voices. In N. K.

Denzin \& Y. S. Lincoln (Eds.), The Sage handbook of qualitative research. Thousand Oaks, CA: Sage Publications, Inc.

Creswell, J. W. (2007). Qualitative inquiry \& research design: Choosing among five approaches. Thousand Oaks: Sage Publications.

Ellis, M. V. (2001). Harmful supervision, a cause for alarm: Comment on Gray et al. (2001) and Nelson and Friedlander (2001). Journal of Counseling Psychology, 48(4), 401-406. doi:10.1037/0022-0167.48.4.401

Ensslen, Anysia J., "Experiences of speech-language pathology graduate students: an exploratory phenomenological study" (2013).Theses and Dissertations-Educational Leadership Studies.Paper 5. http://uknowledge.uky.edu/edl_etds/5

Friedlander, M. L., Keller, K. E., Peca-Baker, T. A., \& Olk, M. E. (1986). Effects of role conflict on counselor trainees' self-statements, anxiety level, and performance. Journal of Counseling Psychology, 33(1), 73-77. doi:10.1037/0022-0167.33.1.73

Geller, E. (2014). Broadening the "Ports of Entry" for Speech-Language Pathologists: A Reflective Model of Supervision. Perspectives on Administration \& Supervision, 24(2), 51-61. 
Geller, E., \& Foley, G. (2009). Broadening the "Ports of Entry" for Speech-Language Pathologists: A Relational and Reflective Model for Clinical Supervision. American Journal of Speech-Language Pathology, 18, 22-41.

Gillam, R., Roussos, C., \& Anderson, J. (1990). Facilitating Changes in Supervisees' Clinical Behaviors. Journal of Speech and Hearing Disorders, 55, 729-729.

Gray, L. A., Ladany, N., Walker, J. A., \& Ancis, J. R. (2001). Psychotherapy trainees' experience of counterproductive events in supervision. Journal of Counseling Psychology, 48, 371-383.

Kimble, C., \& Turner, G. (2012). University: Student peer mentoring in the clinical training of speech-language pathologists. SIG 11 Perspectives on Administration and Supervision, 22, 12-27.

Lincoln, \& Guba, E. G. (2000). Paradigmatic controversies, contradictions, and emerging confluences. In N. K. Denzin \& Y. S. Lincoln (Eds.), Handbook of qualitative research (2nd ed., pp. 163-188). Thousand Oaks, CA: Sage.

McComas, Karen L., "Tools and Community : How Women Become Researchers in Communication Sciences and Disorders" (2010). Theses, Dissertations and Capstones.Paper 102.

McCrea, E. (2014). Clinical Supervision: Back to the Future. The ASHA Leader, 6-8.

McCrea, E., \& Brasseur, J. (2003). The supervisory process in speech-language pathology and audiology. Boston, MA: Pearson Education.

McMillan, J. H., \& Schumacher, S. (2010). Research in education: Evidence-based inquiry (7th ed.): Pearson

Moustakas, C. (1994). Phenomenological research methods. Thousand Oaks, CA: Sage.

Nelson, M. L., \& Friedlander, M. L. (2001). A close look at conflictual supervisory relationships: The trainee's perspective. Journal of Counseling Psychology, 48, 384-395.

Newman, W. (2005). The Basics of Supervision. The ASHA Leader, 12-31.

O'Connor, L. (2008, April 15). A Look at Supervision in the 21st Century. The ASHA Leader, 14-18.

Ostergren, J. (2011). The First year of professional service in speech-language pathology: Supervisory role, working relationships, and satisfaction with supervision. 
Contemporary Issues in Communication Science and Disorders, 38(Spring 2011), $61-75$.

Pasupathy, R., \& Bogschutz, R. (2013). An Investigation of graduate speech-language pathology students' SLP clinical self-efficacy. Contemporary Issues in Communication Science and Disorders, 40 (Fall 2013), 151-159.

Saras, L., \& Post, D. (2008). Supervisory Responses to Critical Teaching Incidents During Speech-Language Therapy. The Clinical Supervisor, 121-137.

Schön, D. A. (1987). Educating the Reflective Practitioner: Towards a New Design for Teaching and Learning in the Professions. San Francisco: Jossey-Bass.

Schwandt, T. A. (2001). Dictionary of qualitative inquiry (2nd ed.). Thousand Oaks, CA: Sage.

Shapiro, D., \& Anderson, J. (1989). One Measure of Supervisory Effectiveness in Speech-Language Pathology and Audiology. Journal of Speech and Hearing Disorders, 54, 549-557.

Taylor, K., White, E., Kaplan, R., \& O'Rourke, C. M. (2012). University: The supervisory process in speech-language pathology: Graduate students' perspective. Perspectives on Administration \& Supervision, 22(2), 47-54.

vanManen, M. (1990). Researching lived experience: Human science for an action sensitive pedagogy. London, Ontario, Canada: The University of Western Ontario.

Wagner, B., \& Hess, C. (1997). Supervisees' Perceptions of Supervisors' Social Power in Speech-Language Pathology. American Journal of Speech-Language Pathology, 90-95.

Yow, V. R. (2005). Recording oral history: A guide for the humanities and social sciences. Lanhan, MD: Altamira Press. 


\section{APPENDIX A}

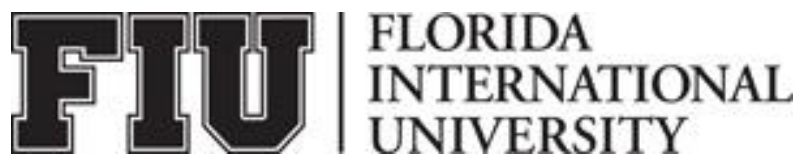

\section{ADULT CONSENT TO PARTICIPATE IN A RESEARCH STUDY}

A Qualitative Assessment of What Comprises an Effective and Positive SupervisorStudent Clinician Relationship in Speech-Language Pathology

\section{PURPOSE OF THE STUDY}

You are being asked to be in a research study. This research is being conducted by Professor Jean S. Mead, EdD, CCC-S and Jessica Atick Fencel. The purpose of this study is to gain a better understanding of graduate students' perceptions, perspectives, and understanding regarding their clinical practicum supervisor experience.

You are being asked to participate because you are/were a graduate student at FIU in the Department of Communication Sciences and Disorders.

\section{NUMBER OF STUDY PARTICIPANTS}

Ten graduates students currently enrolled in FIU's speech-language pathology master's degree program are being asked to participate.

\section{DURATION OF THE STUDY}

The anticipated project period will be December 14, 2015- May 1, 2016. During this time, you will be contacted once or twice to discuss your experience.

\section{PROCEDURES}

If you agree to be in the study, we will ask you to do the following things:

- Complete a one-page demographic form

- Individual interview. This will take approximately 20-30 minutes to complete.

\section{RISKS AND/OR DISCOMFORTS}

There are minimal risks to participating in this study. To minimize the possible risk of breach of confidentiality, data collection forms will be stored in a locked cabinet in a locked office. Other than the above mentioned, the risk level of participating in this project is no greater that that encountered while engaging in any online course.

Participation in the study is optional.

\section{BENEFITS}

Participating in the experience may be beneficial to you as a way to gain a clearer understanding of the supervisory process and enhancing your clinical experiences. 


\section{ALTERNATIVES}

There are no known alternatives available to you other than not taking part in this study. However, any significant new findings developed during the course of the research which may relate to your willingness to continue participation will be provided to you.

\section{CONFIDENTIALITY}

The records of this study will be kept private and will be protected to the fullest extent provided by law. In any sort of report we might publish, we will not include any information that will make it possible to identify a subject. Research records will be stored securely and only the researcher will have access to the records. However, your records may be reviewed for audit purposes by authorized University or other agents who will be bound by the same provisions of confidentiality.

\section{COMPENSATION \& COSTS}

There are no compensations for participating in the study.

\section{RIGHT TO DECLINE OR WITHDRAW}

Your participation in this study is voluntary. You are free to participate in the study or withdraw your consent at any time during the study. Your withdrawal or lack of participation will not affect any benefits to which you are otherwise entitled. The investigator reserves the right to remove you without your consent at such time that they feel it is in the best interest.

\section{RESEARCHER CONTACT INFORMATION}

If you have any questions about the purpose, procedures, or any other issues relating to this research study you may contact Jessica Atick Fencel at jatic001@ @iu.edu.

\section{IRB CONTACT INFORMATION}

If you would like to talk with someone about your rights of being a subject in this research study or about ethical issues with this research study, you may contact the FIU Office of Research Integrity by phone at 305-348-2494 or by email at ori@fiu.edu.

\section{PARTICIPANT AGREEMENT}

I have read the information in this consent form and agree to participate in this study. I have had a chance to ask any questions I have about this study, and they have been answered for me. I understand that I will be given a copy of this form for my records.

Signature of Participant

$$
\text { Date }
$$

Printed Name of Participant

Signature of Person Obtaining Consent

Date 


\section{APPENDIX B}

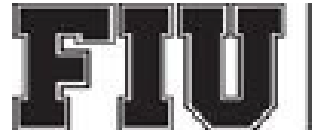

FLORIDA

INTERNATIONAL

UNIVERSITY

Office of Research Integrity

Research Compliance, MARC 270

\section{MEMORANDUM}

To:

Dr. Jean Mead

$\mathrm{CC}$ :

From:

File

Date:

Maria Melendez-Vargas, MIBA, IRB Coordinator

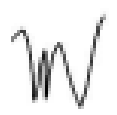

Protocol Title: "A Qualitative Assessment of What Comprises an Effective and Positive Supervisor-Student Clinician Relationship in Speech-Language Pathology"

The Florida Intemational University Office of Research Integrity has reviewed your research study for the use of human subjects and deemed it Exempt under 46.101(b) (1) of the Common Rule via the Exempt Review process.

IRB Protocol Exemption \#: $\quad$ IRB-15-0350 IRB Exemption Date: $10 / 02 / 15$

TOPAZ Reference \#: $\quad 103934$

As a requirement of IRB Exemption you are required to:

1) Submit an Event Form and provide immediate notification of:

- Any additions or changes in the procedures involving human subjects.

- Every serious or unusual or unanticipated adverse event as well as problems with the rights or welfare of the human subjects.

2) Submit a Project Completion Report Form when the study is finished or discontinued.

Special Conditions: N/A

For further information, you may visit the IRB website at http://research.fiu.edu/irb. 


\section{APPENDIX C}

\section{Interview Sub-questions}

a. Did you have an understanding of what were her/his expectations from you?

b. How did she/he make you feel?

c. Is there a specific experience that was particularly (positive/negative)?

d. What did you learn from this experience?

e. As a future supervisor, is there anything you would do differently than this supervisor?

f. Is there anything you would adopt from this supervisor? 


\section{APPENDIX D \\ Themes \& Sub-themes}

Theme 1. ASHA's Task 1 of Supervision: "Establishing and maintaining an effective working relationship with the supervisee."

Subtheme 1. Competency 1.1 and 1.9 respectively:

i. Facilitate an understanding of the clinical and supervisory processes

ii. Establish joint communications regarding expectations and responsibilities in the clinical and supervisory processes

\section{Subtheme 2. Competency $1.3,1.5$, and 1.8 respectively:}

i. Interact from a contemporary perspective with the supervisee in both the clinical and supervisory process

ii. Apply skills of interpersonal communication in the supervisory process

iii. Interact with the supervisee objectively"

\section{Subtheme 3. Competency 1.4:}

i. Apply learning principles in the supervisory process

\section{Subtheme 4. Competency 1.7}

i. Maintain a professional and supportive relationship that allows supervisor and supervisee growth

Theme 2. Anderson's Continuum Model of Supervision 